\title{
Robotic-Assisted Thymectomy in Patients with Nonthymomatous Myasthenia Gravis
}

\author{
Iskander Al-Githmi \\ Department of Surgery, Division of Cardiothoracic Surgery, King Abdulaziz University Hospital, Jeddah, \\ Saudi Arabia \\ E-mail: algithmi@hotmail.com
}

Received August 2, 2011; revised August 23, 2011; accepted September 1, 2011

\begin{abstract}
Complete removal of the thymus and fatty tissue adherent to pericardium is crucial for treating myasthenia gravis. Our aim was to analyze our surgical and clinical results and early experience of robot-assisted thymectomy in patients with nonthymomatous myasthenia gravis. Between January 2008 and October 2010, 8 patients, all women, with nonthymomatous myasthenia gravis underwent robot-assisted thymectomy using a 3-port, left-sided approach. There were no operative mortality; 1 patient had left phrenic nerve injury. Complete remission was achieved in $25 \%$ of the patients at 18 months' follow-up. There was no significant agreement between preoperative computed tomography and histopathology finding $(\mathrm{kappa}=0.059 ; P=0.85)$ and no significant correlation between age and duration of symptoms $(P=0.51)$. Robotic-assisted thymectomy is promising procedure. It can be performed safely and effectively. With follow-up greater than 12 months, $87.5 \%$ of the patients who underwent robot-assisted thymectomy demonstrated clinical improvement.
\end{abstract}

Keywords: Myasthenia Gravis, Nonthymoma, Robot, Thymectomy

\section{Introduction}

Myasthenia gravis is an autoimmune disease affecting postsynaptic nicotinic acetylcholine receptors at the neuromuscular junction block producing neuromuscular transmission-producing muscular weakness of striated muscles.

Thymectomy is an established therapy in treating myasthenia gravis. Ferdinand Sauerbruch performed the first successful thymectomy in a patient with myasthenia gravis in 1911 in Zurich [1]. The efficacy of thymectomy depends on complete removal of all thymic tissue. In 1941, Blalock said, "Complete removal of all thymus tissue offers the best chance of altering the course of the disease" [2].

Multiple described surgical approaches to thymectomy include transcervical thymectomy [3], transsternal thymectomy [4], infrasternal subxiphoid mediastinoscopic thymectomy [5], and video-assisted thoracoscopic thymectomy [6-8]. Introduction of robotic surgical-assisted system contributed to the field of minimally invasive surgery [9]. Yoshino described the first robotic thymectomy in treating small thymoma [10]. However; ro- bot-assisted thymectomy has been reported with good short-term results. Only scant data are available on the long-term results of robot-assisted thymectomy for myasthenia gravis. It is uncertain which patients may benefit from robot-assisted thymectomy. This study sought to analyze the surgical and clinical results of robot-assisted thymectomy in patients with nonthymomatous myasthenia gravis.

\section{Materials and Methods}

Between January 2008 and October 2010, 8 patients all women (mean age, $28 \mathrm{y}$; range, 16 - $46 \mathrm{y}$ ) with nonthymomatous myasthenia gravis referred by neurologists underwent robot-assisted thymectomy by 1 cardiothoracic surgeon at King Abdulaziz University Hospital, Jeddah, Saudi Arabia. Preoperative patient clinical characteristics, duration of symptoms, preoperative acetylcholine receptors antibody, preoperative Osserman classification, and computed tomogram of chest finding are shown in (Table 1).

The diagnosis of myasthenia gravis was based on clinical features, result of electromyography (decrement- 
Table 1. Preoperative demographic data.

\begin{tabular}{ll}
\hline Patient Characteristics & Number \\
\hline Mean age (y) & $28(16-46)$ \\
Mean symptoms duration (m) & $7.75(3-12)$ \\
CT scan chest & \\
- Hyperplasia & $3(37.5 \%)$ \\
- Normal & $5(62.5 \%)$ \\
Acetylcholine receptor antibody & \\
- Positive & $5(62.5 \%)$ \\
- Negative & $3(37.5 \%)$ \\
Osserman stage & \\
- Stage I & \\
- Stage IIa & $0(0.0 \%)$ \\
- Stage IIb & $2(25 \%)$ \\
- Stage III & $5(62.5 \%)$ \\
- Stage IV & $0(0.0 \%)$ \\
Medications & $1(12.5 \%)$ \\
- Anticholinestrase & \\
- Steroid Azathioprine & \\
\hline
\end{tabular}

tal response to repetitive nerve stimulation), and/or demonstration of circulating antibodies against acetylcholine receptors.

Osserman classification was used for myasthenia gravis staging: stage I, ocular myasthenia gravis; stage IIa, mild generalized myasthenia gravis; stage IIb, moderate myasthenia gravis with bulbar involvement; stage III, acute fulminant myasthenia gravis; and stage IV, severe late myasthenia gravis (Table 2).

Preoperative evaluation included thoracic computed tomographic scan and pulmonary function test in all patients. Preoperative preparation included 3 sessions of plasmapheresis in all patients. Informed consent was obtained from all patients after explaining the procedure, different approach of surgical technique, and potential complications. The surgeries were performed using the de Vinci system (Intuitive Surgical, Sunnyvale, CA, USA) through a 3-port left-sided approach. The De

Table 2. Modified osserman classifications.

\begin{tabular}{cl}
\hline Stage & \multicolumn{1}{c}{ Definition } \\
\hline I & $\begin{array}{l}\text { Ocular myasthenia gravis: involvement of extraocular } \\
\text { muscles with diplopia and ptosis. } \\
\text { Mild generalized myasthenia gravis: ocular symptoms are } \\
\text { associate to slow involvement of bulbar (dysphagia and } \\
\text { dysarthria) and skeletal muscles (generalized weakness). } \\
\text { Respiratory muscles are spared. }\end{array}$ \\
IIb & $\begin{array}{l}\text { Moderately generalized myasthenia gravis: progressive } \\
\text { onset of symptoms with significant manifestation of } \\
\text { weakness. Respiratory muscles are spared. }\end{array}$ \\
& $\begin{array}{l}\text { Acute myasthenia gravis: rapid onset (within } 6 \text { months) of } \\
\text { severe bulbar and skeletal muscles involvement with } \\
\text { important weakness. Respiratory muscles are involved. }\end{array}$ \\
IV & $\begin{array}{l}\text { Severe late myasthenia gravis: progressive in severity for } \\
\text { 2 or more years. }\end{array}$ \\
\hline
\end{tabular}

Filippi classification was used for postoperative outcome clinical assessment (Table 3).

\section{Surgical Technique}

After general anesthesia induction avoiding the use of nondepolarizing neuromuscular blocking agents, a double-lumen endobronchial tube was placed for single lung ventilation. The patient was placed in a supine position with the left arm positioned as far back as possible to gain enough space for robotic arms. Three skin incisions were made along the left submammary fold; the camera port (30-degree angled lens) was introduced through fifth intercostal space along anterior axillary line. The right and left robotic arms were introduced through fifth intercostal space, midclavicular, and through third intercostal space, anterior to midaxillary line. The point of reference to anterior mediastinum was the left phrenic nerve. The left arm had an EndoWrist precise grasper; the right arm has EndoWrist harmonic shear dissector. After the robotic system was engaged, dissection started inferiorly at the left pericardio-phrenic angle, and extended superiorly along the left phrenic nerve to the jugular fold and continued inferiorly along retrosternal area; the right pleural space was opened. The inferior horn of thymus gland was isolated from the pericardium and mobilized upwards. The dissection continued on the right side with visualization of the right mediastinal pleura and the right inferior horn. Isolation continued to the neck until the superior horns were identified and isolated. The innominate vein was identified, and dissection continued along the border of the innominate vein to the point where the thymic veins were identified, clipped, and divided. The thymus gland and mediastinal fatty tissue were removed en bloc, placed in endo-bag, and retrieved through a trocar incision.

\section{Results}

The duration of symptoms ranged from 3 to 12 months (mean, 7.75 months). The preoperative Osserman classification was stage IIa in 2 patients; stage IIb in 5 patients; and stage IV in 1 patient. Anti-acetylcholine receptor antibody was positive in 5 patients $(62.5 \%)$ and negative

Table 3. De Filippi postoperative classification.

\begin{tabular}{cl}
\hline Class & \multicolumn{1}{c}{ Description } \\
\hline 1 & Complete remission, no medication. \\
2 & Asymptomatic, decreased medication. \\
3 & $\begin{array}{l}\text { Improved, decreased symptoms or decreased } \\
\text { medication. }\end{array}$ \\
4 & No change. \\
5 & Worsening symptoms. \\
\hline
\end{tabular}


Table 4. Selected preoperative variables and patient outcome.

\begin{tabular}{|c|c|c|c|c|c|c|c|c|}
\hline & & \multirow{2}{*}{$\begin{array}{c}\text { Osserman } \\
\text { classification }\end{array}$} & \multirow{2}{*}{$\begin{array}{c}\text { Symptoms } \\
\text { duration (month) }\end{array}$} & \multirow{2}{*}{ Preop CT chest } & \multirow{2}{*}{ Histopathology } & \multicolumn{3}{|c|}{ Follow-up/De Filippi Classification } \\
\hline & & & & & & 6 months & 12 months & 18 months \\
\hline 1 & 16 & IIb & 12 & Hyperplasia & Thymic involution & Class 4 & Class 3 & Class 2 \\
\hline 2 & 19 & $\mathrm{IIb}$ & 3 & Normal & Normal & Class 4 & Class 2 & Class 3 \\
\hline 3 & 23 & IIa & 12 & Normal & Normal & Class 4 & Class 3 & Class 3 \\
\hline 4 & 26 & $\mathrm{IIb}$ & 12 & Hyperplasia & Normal & Class 4 & Class 4 & Class 3 \\
\hline 5 & 28 & $\mathrm{IIb}$ & 5 & Hyperplasia & Hyperplasia & Class 3 & Class 3 & Class 2 \\
\hline 6 & 30 & IV & 3 & Normal & Hyperplasia & Class 3 & Class 2 & Class 1 \\
\hline 7 & 36 & $\mathrm{IIb}$ & 7 & Normal & Hyperplasia & Class 3 & Class 3 & Class 2 \\
\hline 8 & 46 & $\mathrm{IIb}$ & 8 & Normal & Thymic involution & Class 3 & Class 2 & Class 1 \\
\hline
\end{tabular}

in 3 patients $(37.5 \%)$. The preoperative thoracic computed tomogram showed normal anterior mediastinum in 5 patients $(62.5 \%)$ and an enlarged thymic gland in 3 patients $(37.5 \%)$. The operative time ranged from 88 to 300 minutes (mean, $260 \mathrm{~min}$ ). All patients were extubated in the operating suite. There was no operative mortality. One patient developed postoperative myasthenia crisis on day 3 and required endotracheal intubation and mechanical ventilation and was successfully managed with plasmapheresis and weaned of mechanical ventilation on postoperative day 9. One patient had left phrenic nerve injury. Histopathologic examination of the specimens revealed normal thymus in 3 patients $(37.5 \%)$, thymic hyperplasia in 3 patients $(37.5 \%)$, and thymic involution in 2 patients $(25 \%)$. Additionally, histopathologic findings correlated with preoperative computed tomogram of chest, revealing hyperplasia in 2 patients $(25 \%)$, which was reported normal on preoperative computed tomogram that was not clinically significant (kappa $=0.059 ; P=0.85$ )

Six months' follow-up showed improvement, decreased symptoms (class 3 ) in 4 patients $(50 \%)$, and no change in symptoms or decreased medication in 4 patients (50\%). Twelve months' follow-up showed a symptomatic, decreased medication (class 2) in 3 patients $(37.5 \%)$ and improvement, decreased medication (class 3 ) in 4 patients $(50 \%)$. One patient $(12.5 \%)$ experienced no change in symptoms or decreased medication (class 4). At 18 months, complete remission was shown in 2 patients (25\%), a symptomatic, decreased medication (class 2) in 3 patients $(37.5 \%)$, and improvement, decreased medication (class 3 ) in 3 patients (37.5\%) (Table 4).

\section{Discussion}

Thymectomy is an established therapy in treating myasthenia gravis combined with medical treatment [11]. Robot-assisted thymectomy is promising technique; however, complete removal of the thymus gland is crucial. Compared with video-assisted thoracoscopic thymectomy, the robot-assisted technique provides several advantages, particularly, in the corner of anterior medi- astinum, which is difficult to reach with video-assisted thoracoscopy. In addition, 3-dimensional visualization, high-dexterity, and full range motion of EndoWrists, make the robot system safe and efficient. We adopt the left-sided approach and the use of pneumomediastinum to facilitate dissection of thymus gland and perithymic fatty tissue as proposed by Mineo and colleagues [6]. We believe that left-sided approach offers excellent visualization of the left pericardiophrenic angle and aortopulmonary window.

Our postoperative clinical results are good. Clinical improvement is demonstrated in $87.5 \%$ of patients who underwent robot thymectomy at follow-up greater than 12 months. These results are comparable to those reported by others through a transsternal approach [4]. In addition, clinical improvement continued over time, as we have noted that complete remission is achieved in $25 \%$ of patients at 18 months' follow-up. Regarding preoperative computed tomogram of chest and histologic findings, we observed no clinical significant correlation in patients with nonthymomatous myasthenia gravis referred for thymectomy. This suggests that preoperative computed tomogram has a limited role in differentiating the nonthymomatous pathology in patients with myasthenia gravis. In addition, we observed no significant correlation between symptom duration and age. We were inclined to follow our patients using guidelines set by Jaretski and colleagues [12].

Our study is limited, as the number of patients is small and difficult to perform a multivariate analysis of independent factors that affect the outcome. Long-term follow-up is necessary for proper assessment of clinical results.

\section{References}

[1] E. Schumacher and J. Roth, "Thmymektomie bie Einem Fall Von Morbus Basedowi mit Masthenie," Grenzgeb. d.Med.u. Chir. Vol. 25, 1912, pp. 746-765.

[2] A. Blalock, H. A. McGehee and F. R. Ford, "The Treatment of Myasthenia Gravis by Removal of the Thymus Gland," Journal of the American Medical Association, Vol. 117, No. 18, 1941, pp. 1529-1533. 
[3] R. F. Calhoun, J. H. Ritter, T. J. Guthrie, A. Pestronk, B. F. Meyers, G. A. Patterson, M. S. Pohl and J. D. Cooper, "Results of Transcervical Thymectomy for Myasthenia Gravis in 100 Consecutive Patients," Annals of Surgery, Vol. 230, No. 4, 1999, pp. 555-559. doi:10.1097/00000658-199910000-00011

[4] A. Masaoka, Y. Yamakawa, H. Niwa, I. Fukai, S. Kondo, M. Kobayashi, Y. Fujii and Y. Monden, "Extended Thymectomy for Myasthenia Gravis Patients: A 20-Year Review," Annals of Thoracic Surgery, Vol. 62, No. 3, 1996, pp. 853-859. doi:10.1016/S0003-4975(96)00376-1

[5] A. Uchiyama, S. Shimizu, H. Murai, S. Kuroki, M. Okido and M. Tanaka, "Infrasternal Mediastinoscopic Thymectomy in Myasthenia Gravis: Surgical Results in $23 \mathrm{~Pa}-$ tients," Annals of Thoracic Surgery, Vol. 72, No. 6, 2001, pp. 1902-1905. doi:10.1016/S0003-4975(01)03210-6

[6] T. C. Mineo, E. Pompeo, T. E. Lerut, G. Bernardi, W. Coosemans and I. Nofroni, "Thoracoscopic Thymectomy in Autoimmune Myasthesia: Results of Left-Sided Approach," Annals of Thoracic Surgery, Vol. 69, No. 5, 2000, pp. 1537-1541. doi:10.1016/S0003-4975(00)01237-6

[7] M. J. Mack, R. J. Landreneau, A. P. Yim, S. R. Hazelrigg and G. R. Scruggs, "Results of Video-Assisted Thymectomy in Patients with Myasthenia Gravis," Journal of Thoracic and Cardiovascular Surgery, Vol. 112, No. 5, 1996, pp. 1352-1359.

doi:10.1016/S0022-5223(96)70151-4
[8] R. Vizeteu, M. Damian, B. Smeu, A. Stoica, V. Culman, O. Băjenaru and A. Ene, "Video-Assisted Thoracoscopic Extended Thymectomy (VATET) with Cervical Approach for Myasthenia Gravis-Initial Experience [in Romanian]," Chirurgia (Bucur). Vol. 105, No. 6, 2010, pp. 797-803.

[9] M. Hashizume, K. Konishi, N. Tsutsumi, S. Yamaguchi and R. Shimabukuro, "A New Era of Robotic Surgery Assisted by a Computer-Enhanced Surgical System," Surgery, Vol. 131, Supplement 1, 2002, pp. S330-S333.

[10] I. Yoshino, M. Hashizume, M. Shimada, M. Tomikawa, M. Tomiyasu, R. Suemitsu and K. Sugimachi, "Thoracoscopic Thymomectomy with the Da Vinci Computer-Enhanced Surgical System," Journal of Thoracic and Cardiovascular Surgery, Vol. 122, No. 4, 2001, pp. 783-785. doi: $10.1067 / \mathrm{mtc} .2001 .115231$

[11] A. E. Papatestas, L. I. Alpert and K. E. Osserman, "Studies in Myasthenia Gravis: Effects of Thymectomy Results on 185 Patients with Nonthymomatous and Thymimatous Myasthenia Gravis," American Journal of Medicine, Vol. 38, 1971, pp. 580-585.

[12] A. Jaretzki, R. J. Barohn, R. M. Ernstoff, H. J. Kaminski, J. C. Keesey, A. S. Penn and D. B. Sanders, "Myasthenia Gravis: Recommendations for Clinical Research Standards. Task Force of the Medical Scientific Advisory Board of the Myasthenia Gravis Foundation of America," Annals of Thoracic Surgery, Vol. 70, No. 1, 2000, pp. 327-334. doi:10.1016/S0003-4975(00)01595-2 